\section{PORPHYRIA CUTANEA TARDA IN RELAPSE : A CASE REPORT}

BY

\author{
R. J. CALVERT, M.B., B.Sc., M.R.C.P. \\ AND
}

\section{RIMINGtON, M.A., Ph.D., D.Sc.}

(The Medical Unit, Whipps Cross Hospital, London, E.11, and Department of Chemical Pathology, University College Hospital Medical School, London, W.C.1)

The relative frequency of the various types of porphyria (Waldenström, 1937; Watson, 1951) is calculable only from observation upon large series. Watson and colleagues (1951), reporting 88 cases of porphyria, observed over a 14-year period, found only 5 patients with congenital porphyria, 10 with "mixed" (cutanea tarda) porphyria, and 73 with acute porphyria. Nevertheless, porphyria cutanea tarda may be much more common than is supposed (Macgregor, Nicholas, and Rimington, 1952 ; Wells and Rimington, 1953), since "attacks" or exacerbations may closely simulate those of acute porphyria; unless a stool porphyrin determination is carried out during remission, a distinction is at times hardly possible. The finding of normal urinary porphyrin in a patient seen only in the remission phase might lead to the exclusion altogether of porphyria from the diagnosis, but a stool porphyrin determination will always reveal the excessive total porphyrin excretion. Increased vigilance in dermatological case material might be rewarding. Brunsting and associates (1951) referred to 21 cases of the adult form of chronic porphyria with cutaneous manifestations seen at the Mayo Clinic in the previous six years.

The case described below was first seen during the course of an attack, and only on one day were porphobilinogen and uroporphyrin present in the urine, although both coproporphyrin and protoporphyrin were regularly present in considerable amount. As the attack subsided, the faecal porphyrin rose and urinary porphyrin diminished.

\section{Case Report}

A mechanic aged 26 was admitted as a surgical case to Whipps Cross Hospital on March 12, 1952. His chief complaints were central abdominal colic, frequent vomiting, and inability to pass faeces or flatus for three days. He had a generalized exudative skin eruption of three weeks' duration, following on crops of vesicles one month previously. There had been three similar episodes of vesication in the previous two years. Vesicles cleared within a fortnight on two of these occasions. On the third, which occurred one week after the injection of varicose veins with "ethamolin" (5\% ethanolamine oleate, B.P., in $2 \%$ benzyl alcohol), he was admitted to a dermatological unit and was discharged a fortnight later with a diagnosis of sensitization dermatitis. He had taken no barbiturate drugs during or immediately before this incident. No relative had suffered from vesication similar to that of our patient so far as inquiry indicated. Neither the patient nor his parents could recall having passed dark or red urine. The patient stated that he was a strict total abstainer from alcohol.

Physical examination revealed a robust and plethoric man, who stated that he had recently weighed 14 stone $(88.9 \mathrm{~kg}$.). Small weeping lesions were observed on his forehead. His " rosy apple" complexion was partly due to telangiectatic vessels. These bore no resemblance to the angiomatous lesions of Osler's disease or to spider naevi. The knees were constantly flexed. Physical signs, apart from skin manifestations, were confined mainly to the abdomen, which appeared somewhat distended, but moved with respiration. The percussion note was resonant throughout, but bowel sounds were absent and no peristalsis was observed. Neither rebound tenderness nor palpable masses were found. The hernial orifices were clear and rectal examination was negative. There was an intense desire to pass flatus, but inability to do so.

Violaceous areas were noticed on the lower outer aspects of the legs, while scattered weeping lesions were observed on the upper limbs and trunk. Mottled palmar erythema and a few small scars were seen on the hands. Temperature and routine urinary analysis were normal ; the blood pressure was $115 / 80$. A provisional diagnosis of subacute obstruction of the small intestine was made. A straight $x$-ray film of the abdomen partly supported this diagnosis by revealing gaseous distension, but without actual fluid levels. Agonizing abdominal colic persisted, and on the following day (March 13) laparotomy was performed, but there was no demonstrable lesion.

\section{Progress}

On March 16 the patient developed a psychosis with confusional, depressive, hysterical, and paranoid features, lasting one week. The urine, which previously was orangecoloured, now had a burgundy hue. A clinical diagnosis of porphyria was made, and was confirmed chemically. The urine showed red fluorescence in ultra-violet light, while the Watson-Schwartz test for porphobilinogen was positive. On March 17 pentobarbitone sodium, $3 \mathrm{gr}$. (0.2 g.) nocte, was given. On the 18th a right-sided facial paresis appeared, without other neurological signs. The bowels were opened and he passed flatus. The skin lesions had now almost disappeared. Next day phenobarbitone, 1 gr. $(65 \mathrm{mg}$.), was given, but on March 20 all barbiturates were prohibited. On the 25th a flaccid quadriplegia with urinary incontinence was present.

By March 27, although orientated and rational, he was apathetic and readily lost the power of concentration. He had a bilateral partial ptosis, but the right-sided facial weakness was now scarcely demonstrable. The pupils were large, equal, and reacted slowly to light. Eye movements were full and there was neither nystagmus nor diplopia. The fundi and visual fields were normal. The corneal reflexes were sluggish, but the pharyngeal reflex was brisk. There were neither meningeal nor bulbar signs.

The remaining signs were confined to the limbs, where gross weakness without fasciculation was demonstrable, especially in the girdle regions. Limb reflexes were absent apart from a minimal response in the ankle-jerks. The plantar responses were flexor. Sensory loss was restricted to the upper limbs, where he was unable to discriminate between a sharp prick and blunt pressure.

A tachycardia (118 a minute) and a moderate hypotension $(95 / 75)$ occurred. The abdominal colic, although controlled by pethidine ( $100 \mathrm{mg}$. intramuscularly), recurred during the next three weeks. The sensory loss and ptosis disappeared after three days, but recovery from the quadriplegia was so gradual that even at the end of six months he was only just able to walk unaided.

Six weeks after admission two fresh signs involving the appendages and skin were apparent. These were the presence of Beau's lines on the nails, producing a transverse groove just distal to the lunula, and the development of a melanosis of the forehead, neck, and extensor surfaces of the forearms. The latter cleared over the next four months.

\section{Investigations}

Serial values for blood counts, serum electrolytes, and hepatic tests are indicated in Table I. There was pronounced elevation of the first blood urea result and of the first two leucocyte counts. This leucocytosis could be partly attributed to the development of suppuration at the site of 
TABLE I.-Blood Chemistry and Liver-function Tests

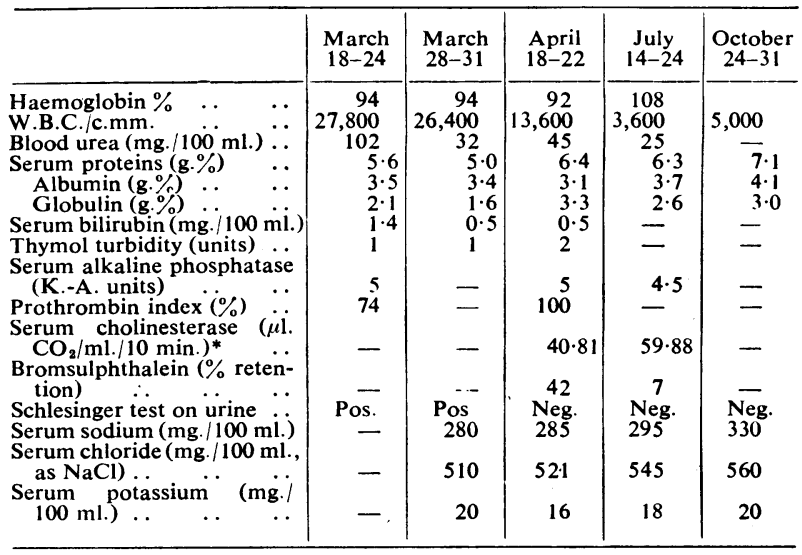

* Lower limit of normal $=30$

the abdominal wound. Some impairment of liver function was evident (serum proteins, cholinesterase activity, prothrombin index, also bromsulphthalein retention, serum bilirubin, and urinary urobilin). No associated proteinuria was demonstrable. Electrophoresis of plasma proteins (April 20) revealed no gross alteration from the normal ratio. The E.S.R. was normal. The plasma pyruvic acid level (March 20) was $0.8 \mathrm{mg}$. per $100 \mathrm{ml}$., a value within normal limits. The Wassermann reaction was negative:

Electrolyte metabolism was also deranged. Thus prolonged low levels of serum sodium and chloride were observed. Serum potassium values remained within normal limits. No abnormality in adrenal function was demonstrable. The Kepler water-diuresis test yielded normal results (April 19 and July 23), while the Thorn test (April 9) showed an adequate eosinopenic response.

A limited investigation of renal function was carried out. In the first week in hospital, two catheter specimens of urine showed no microscopical abnormality. The urea concentration and urea clearance tests gave normal results, but were not conducted until four months after his admission.

A plain $x$-ray film of the abdomen (March 17) revealed gaseous distension. A barium meal with follow-through studies (May 19) showed dilatation of the terminal ileum with segmentation of the barium. The time taken for the barium to pass through the intestines was within normal limits.

Electromyography (May 8) showed no nerve conduction from the left brachial plexus when this was stimulated over Erb's point. On exploration of the left deltoid and biceps the motor activity on volition was.grossly decreased to the point of being discrete, while fibrillation was present at rest. The results suggested gross denervation of the type found in polyneuritis.

Exposure to ultra-violet light and to the carbon arc lamp (April 4) was conducted when his abdominal colic appeared to have subsided. The volar surface of the left forearm was exposed to the ultra-violet lamp for periods of one-half. one, and one and a half minutes without producing any local reaction in the next two days. The back of the left forearm was exposed to the carbon arc lamp for four minutes without local reaction, but after the first three minutes he complained of a recurrence of colic. This was so severe that he could not speak, but it lasted only a few hours.

Skin biopsy (September 8) of the right forearm over a melanotic area showed atrophic skin with no dermal papillae, and there was dense melanin pigmentation of the basal layer. Iron was present and mucoid material was demonstrable in the corium.

Serial electrocardiograms were normal.

Porphyrin Determinations. - The serum showed a red fluorescence to ultra-violet light on March 25, regressing to a faint but definite fluorescence three days later. The urine was analysed on six occasions between March 25 and April 6. Porphobilinogen was present on the first occasion only. Stool porphyrins were determined on April 6, and again on April 22 and July 5. The results of these investigations are recorded in Table II, together with a follow-up in March, 1953.

The stool of July 5 contained the large amount of $2 \mathrm{mg} . / \mathrm{g}$. dry weight of porphyrin (upper normal limit, $30 \mu \mathrm{g} . / \mathrm{g}$. dry weight) at a time when the urine contained only $0.73 \mathrm{mg}$. $/ \mathrm{l}$. total porphyrin. This relationship is characteristic of porphyria cutanea tarda in remission.

TABLE II.-Porphyrin Content of Urine and Stool Specimens

\begin{tabular}{|c|c|c|c|c|}
\hline Date & $\begin{array}{c}\text { Uro- } \\
\text { porphyrin }\end{array}$ & $\begin{array}{c}\text { Copro- } \\
\text { porphyrin }\end{array}$ & $\begin{array}{c}\text { Proto- } \\
\text { porphyrin }\end{array}$ & $\begin{array}{c}\text { Porpho- } \\
\text { bilinogen }\end{array}$ \\
\hline $\begin{array}{l}\text { Urine } \\
25 / 3 / 52 \\
27 / 3 / 52 \\
28 / 352 \\
31 / 3 / 52 \\
2 / 452 \\
6 / 4 / 52 \\
5 / 752 \\
15 / 3 / 53\end{array}$ & $\begin{array}{c}8 \cdot 3 \mathrm{mg} / 24 \mathrm{hr} . \\
\mathrm{Nil} \\
, " \\
, " \\
, " \\
. "\end{array}$ & 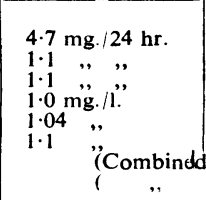 & $\begin{array}{l}1.9 \mathrm{mg} . / 24 \mathrm{hr} . \\
4.0 \\
0.4 \mathrm{mg} . / 1 . " \\
1.65 \\
1.9 \% " \\
0.73 \mathrm{mg} . / 1 . \\
0.39 \%\end{array}$ & $\begin{array}{l} \pm \\
= \\
= \\
= \\
=\end{array}$ \\
\hline $\begin{aligned} \text { Stool } \\
6 / 4 / 52 \\
22 / 4 / 52 \\
5 / 7 / 52 \\
15 / 5 / 53\end{aligned}$ & ", & 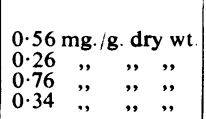 & 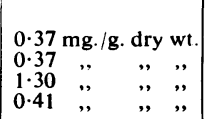 & \\
\hline
\end{tabular}

\section{Discussion}

Porphyria cutanea tarda is the term reserved for cases with late appearance of the skin manifestations which are the usual presenting symptoms. It is a fairly benign condition when the hydroa vacciniforme lesions alone are present. It predominates slightly in males and is usually observed in the third to fifth decades. The salient clinical features are : vesicular and erosive skin lesions, particularly on the backs of the hands and especially following exposure to heat, light, or trauma ; a violaceous complexion, often with suffused sclerae; a tendency to melanotic and sclerodermatous changes; and, occasionally, hypertrichosis. Waldenström (1937) referred, in his original description of this form of porphyria, to the absence of abdominal and nervous symptoms. Later study of the disease has, however, revealed that attacks or exacerbations may occur during which abdominal colic may be mild to severe and paralyses may even be seen (Brunsting et al., 1951 ; Macgregor et al.. 1952).

Porphobilinogen may make its appearance for a few days at the height of the attack, but the quantity is never great and it may even be absent altogether. Urinary porphyrin is generally increased in this disease, but its type is variable. Some patients with marked cutaneous lesions excrete uroporphyrin regularly, and the series I isomer appears to predominate (Canivet and Rimington, 1953); others excrete uroporphyrin (of variable isomer composition) during attacks, together with coproporphyrin and protoporphyrin, while yet others have a normal urinary porphyrin during remission but excrete substantial amounts of coproporphyrin and protoporphyrin during exacerbations. It is indeed difficult to decide whether such different cases illustrate phases in the progression of the disease or whether further subdivision is required into distinct pathological entities. This question can best be answered by watching the progress of known cases and avoiding hasty generalizations. There is, however, one feature common to cases of porphyria cutanea tarda which serves to distinguish them from cases of acute porphyria-namely, the observation that in porphyria cutanea tarda during remission faecal porphyrin is raised much above normal. During attacks it falls as the urinary porphyrin rises, the plasma evinces red fluorescence, and the serum bilirubin is generally raised (Gray, Rimington, and Thomson, 1948; Macgregor, et al., 1952; Wells and Rimington, 1953). 
There is ample clinical and biochemical evidence to support a diagnosis of porphyria cutanea tarda in our patient. The onset with vesicular eruptions is characteristic; however, a diagnosis of acute porphyria would have been difficult to refute in their absence, since the episode of abdominal colic was accompanied in his case by fairly severe involvement of the nervous system, giving a clinical picture closely simulating acute porphyria in relapse.

While the cause of the present attack remains obscure one of the previous attacks was probably precipitated by an injection of the sclerosing agent " ethamolin" into a varicose vein. Apparently this substance has not been previously suggested as a precipitating cause of attacks of porphyria.

Attention has recently been focused on adrenal and hepatic function in porphyria. Linder (1947) thought that the hypochloraemia sometimes found in acute porphyria could not be due to vomiting, since alkalosis is not present; besides, there is usually a co-existent hyponatraemia. In our patient the low values for serum sodium and chloride persisted for several weeks. Although other workers (Abrahams, Gavey, and Maclagan, 1947) have shared the view that an adrenal cause for this is operative, evidence for a renal cause has also been afforded (Prunty, 1949). In this patient the results of tests do not suggest impaired adrenal function, which, if present, would have an obvious bearing on therapy. It may be noted that both Linder (1947) and Abrahams et al. (1947) produced only temporary success by the administration of salt and adrenocortical extract, while trials of A.C.T.H. or cortisone have been negative or at best inconclusive (Oltman and Friedman, 1951; Myerson, 1951: Gilbert, Toupin, and Bell, 1951; Meyers and Griffith, 1952: Goldberg, MacDonald, and Rimington, 1952; Watson, 1952).

Both Davies (1949) and Prunty (1949) consider that a renal rather than adrenal disorder is responsible for the changes in renal tubular function. In our patient, frequent urinalysis and two microscopical examinations of the urine at the height of the illness revealed no abnormality. The blood-urea level, although considerably raised in the first few days after admission, was subsequently within normal limits. The earlier raised value, taken in conjunction with his hypotension and low serum sodium and chloride, suggested that he was then dehydrated, perhaps on account of the post-operative state (Moore and Ball, 1952) and a scanty food and fluid intake at this time.

Frequent reference has been made to impaired hepatic function in porphyria of the acute and cutanea tarda varieties. The results reported here support this view. This subject has been discussed recently by Watson (1952), who has introduced the term "porphyria hepatica" (Watson, 1951) to designate these two types of porphyria where the liver is thought to be mainly responsible for the abnormal porphyrin production, the liver often containing large amounts of porphyrins while values in bone marrow were normal. This situation is reversed in congenital porphyria, which Watson (1951) prefers to call “porphyria erythropoietica."

The radiological signs in cases of porphyria with intestinal colic are well recognized (Mason, Courville and Ziskind, 1933; Nesbitt, 1944; Fisher and Stanley, 1951; Calvy and Dundon, 1952). They consist of segmental gaseous dilatation proximal to the sites of spasm. In the present case barium study revealed segmental dilatation of the intestine, especially involving the caecum.

Electromyographic investigations in paralysis due to porphyria have hitherto received little attention (Massachusetts General Hospital Case Records, 1947; Peters, 1949). The tracings from the present case showed the gross denervation of typical polyneuritis. This was accompanied clinically by acute muscle atrophy as previously described in the case of DiFiore (1946).

The skin biopsy revealed atrophic changes and heavy melanin deposition, as often observed in these cases. The melanosis appeared about six weeks after admission, but had regressed again after a further four months. It involved mainly the upper part of the body, and was well marked in the neck, where it simulated a smear of coal dust. In view of the constipation for the first few weeks after admission, it was wondered whether an associated absorption and skin deposition of indican might explain this pigmentation, but frequent urinary studies failed to show any pathological output of indican, employing the usual reagents of Jaffe, Jolles, and Obermeyer.

The reciprocal urinary/faecal level of porphyrin excretion, previously referred to, was used as an index of commencing remission, and its presence in this case is further confirmation of its occurrence in patients with porphyria cutanea tarda.

Only conservative treatment was adopted, with vitamin-Bgroup supplements. Pethidine was found to be a reliable antispasmodic to control the colic. Other workers have shown that neostigmine (Waldenström, 1944; Opsahl, 1947 ; Gordin, 1948 ; Veflingstad, 1949 ; Öigaard and Roos, 1953) and the ganglion-blocking agent T.E.A.C. (Wehrmacher, 1952) may be useful alternatives. The role of cortisone and A.C.T.H. awaits further evaluation, according to available reports. Watson (1952) refers to remission within 48 hours in three of six cases treated with cortisone or A.C.T.H., but it is not clear to what extent the result was due to the drugs. Other workers have not found any striking alteration of porphyrin excretion in further single cases so treated.

Physiotherapy was beneficial in encouraging recovery of muscle function in our patient, especially when he was bedridden with paralysis. He returned to light work six months after his admission. By a further three months he had regained his usual weight, which had shown a maximal loss of 3 stone $(19 \mathrm{~kg}$.) about four months after admission. Since discharge from hospital he has enjoyed good health, but has been handicapped by residual muscle weakness.

\section{Summary}

Investigation is reported of a case of porphyria cutanea tarda in relapse in which severe colic and neurological disturbances were present in addition to cutaneous manifestations. Porphobilinogen and uroporphyrin were detected in the urine on only one occasion; later, only coproporphyrin and protoporphyrin were present, and as the level of these declined that of the faecal porphyrin rose. Electromyography indicated gross denervation of the type found in polyneuritis. The patient still had residual muscle weakness about one year after his attack.

The relation of porphyria cutanea tarda to acute porphyria and congenital porphyria is discussed, and the origin and treatment of symptoms are briefly considered.

We are indebted to Mr. Lang Stevenson and Dr. Eric Smith for permission to investigate this case. Thanks are also due to Professor Nicholas Martin for electrophoretic study of plasma proteins, to Dr. F. Hobbiger for the cholinesterase determinations, to Dr. William Walther for co-operation in the biochemical determinations, and to Drs. P. Bauwens and A. T. Richardson for the electromyographic investigations. To Drs. A. Stein and P. Blaxland we owe thanks for the report on the surgical aspect of the patient. Dr. C. Raeburn carried out the histological studies. $\mathrm{Mr}$. F. Grover gave valuable technical assistance throughout. One of us (C. R.) wishes to thank the Nuffield Foundation for a grant which has made possible the establishment of a unit for the investigation of pyrrole pigment metabolism.

\section{REFERENCES}

Abrahams, A., Gavey, C. J., and Maclagan, N. F. (1947). Brtilsh Medical Journal, 2, 327

Brunsting, L. A., Mason, H. L., and Aldrich, R. A. (1951). J. Amer. med. Ass., 146, 1207.

Calvy, G. L., and Dundon, C. C. (1952). Radiology, 58, 204.

Canivet, J., and Rimington. C. (1953). Biochem. J., 55, 867.

Davies, D. (1949). British Medical Journal, 1, 846.

DiFiore, J. A. (1946). Med. Clin. N. Amer., 30, 397.

Fisher, S. H., and Stanley, R. R. (1951). Amer. J. Roentgenol., 65, 882. J., 65, 585. 
Goldberg, A., MacDonald, A. C., and Rimington, C. (1952). British Medical Journal, 2, 1174

Gordin, R. (1948). Nord. Med., 37, 480

Gray, C. H., Rimington, C., and Thomson, S. (1948). Quart. J. Med. 17, 123 .

Lancet, 2, 649

Macgregor, A. G.. Nicholas, R. E. H., and Rimington, C. (1952). Arch. intern. Med., $90,483$.

Mason, V. R., Courville, C. B., and Ziskind, E. (1933). Medicine, Baltimore, 12, 355

Massachusetts General Hospital Case Records, Case No. 33031 (1947). New Engl. J. Med., 236, 109.

Meyers, J. B., and Griffith, R. L. (1952). Amer. Practit., Philad., 3, 612.

Moore, F. D., and Ball, M. R. (1952). The Metabolic Response to Surgery. Thomas, Springfield, Illinois.

Myerson, R. M. (1951). Delaware St. med. J., 23, 62

Nesbitt, S. (1944), J. Amer, med. Ass. 124, 286.

Oltman, J. E., and Friedman S. (1951). New Engl. J. Med., 244, 173.

Ö̈gaard, H. and Roos, B. E. (1953), Nord. Med., 49, 411.

Opsahl, R. (1947). Ibid., 34, 930.

Peters, G. A. (1949). Ann. intern. Med., 30, 1237.

Prunty, F. T. G. (1949), J. clin. Invest., 28,690.

Veflingstad, H. (1949), Nord. Med 42, 1432

Waldenström. J. (1937). Acta med. scand. Suppl. 82.

- (1944). Nord. Med., 23, 1562.

Watson. C. J. (1951) Lancet, $1,539$.

- (1952). In Duncan's Diseases of Metabolism, 3rd ed., p. 1079 Saunders, Philadelphia and London.

Lowry, P. T.. Schmid, R. Hawkinson, V. E., and Schwartz, S. (1951).

Trans. Ass. Amer. Phys., 64, 345.

Wehrmacher, W. H. (1952). Arch intern. Med '89, 111.

Wells, G. C., and Rimington, C. (1953). Brit. J. Derm. 65, 337

\section{CUTANEOUS MANIFESTATIONS OF PORPHYRIA}

BY

GEORGE DISCOMBE, M.D., B.Sc.

AND

C. S. TREIP, M.D.

(From the Central Middlesex Hospital, London)

\section{Cutaneous and Visceral Porphyrias}

The porphyrinopathies, diseases in which excessive quantities of a porphyrin or its precursor are excreted in the urine, have a protean symptomatology. The visceral symptoms are now well known, but the cutaneous symptoms are less well understood. Basically, the skin may react in three ways-by vesication, by pigmentation, or by the development of hirsuties.

Vesication usually occurs in spring or summer, when bullae from 1 to $4 \mathrm{~cm}$. in diameter appear on face, hands, forearms, legs, ears, neck, or other exposed areas either as a result of solar irradiation or following slight trauma. The bullae rupture, and heal with scarring, usually mild. If infection occurs granulation tissue is found at the base of the bulla with fibrosis and more severe scarring. "Sclerodermatous" thickening of the skin may result; if the conjunctivae are involved the two layers may fuse. Pigmentation also appears on exposed areas, usually, but not always, after blistering, so that a diagnosis of pellagra (which itself is accompanied by a symptomatic porphyrinuria) is entertained. Hirsuties is uncommon, and usually moderate.

Patients with such skin lesions may be labelled as cases of pemphigus, epidermolysis bullosa, hydroa bullosa, hydroa vacciniforme, eczema solare, lupus erythematosus, erythema exudativum multiforme, summer prurigo, pellagra, or light dermatitis, unless or until the porphyrinuria is discovered. Zeligman and Baum (1948) used the term " porphyric bullous dermatosis" for any combination of these syndromes in a subject found to have a porphyria, while they used the term "epidermalysis bullosa" when blisters developed on exposed areas after slight trauma, and "hydroa aestivale" when blisters developed one to three days after solar irradiation insufficient to cause more than slight inconvenience to a normal subject.

Most workers (Rimington, 1952) agree that true porphyrias are characterized by excretion of uroporphyrin or a precursor, and can be classified into an acute form with colic, constipation, and paralysis, a congenital form with photosensitivity from birth, and porphyria cutanea tarda, in which a bullous dermatosis appears in adult life. We recently studied a patient with porphyria cutanea tarda who died in an attack of acute porphyria.

\section{Case Report}

An unmarried woman born in 1922 was well, with a freckled fair skin, until 1942. There was no relevant family history. In 1942 she noted blistering on her hands only after minor trauma, at any time of the year. In 1945 blisters occurred in w a $\mathrm{rm}$ weather, especially by the sea ; if she took her stockings off blisters appeared on her legs; she also had attacks of moderately severe right-sided abdominal pain with constipation. Hospital investigation was inconclusive ; appendicectomy showed a fibrosed appendix, but within a week three more attacks of abdominal pain, now with vomitin $\mathrm{g}$, occurred ; thereafter she continued to blister, though the attacks of pain ceased.

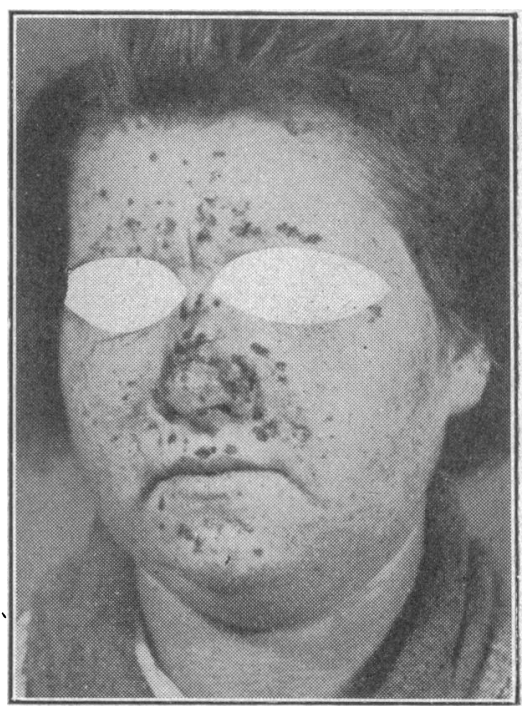

Fig. 1.-Showing crusts on face.
On July 16, 1950, she complained of aching in the legs, pins-and-needles in the hands and feet, swelling of the face, aching breasts, vomiting, frequency of micturition, dysuria, and the passing of dark urine. Her symptoms improved on sulphadimidine, but she was readmitted on July 26. She was plump and cheerful, with a dark, earthy complexion and a slightly swollen face covered with freckles. She had koilonychia of two fingers, no anaemia, and no abnormal physical signs except a blood pressure of $140 / 90$, tenderness in the right iliac fossa, sluggish tendon reflexes, and slight hypotonia. She was very constipated and missed a menstrual period. Investigations were fruitless. On July 22 she complained of an irritating rash on the face and nose.

When seen on August 8 in the routine follow-up she had a yellow skin and conjunctivae, puffy hands and face, with a scabbing eruption of the face (Fig. 1) and a paronychial bullous eruption of the hands. A clinical diagnosis of hydroa aestivale was made, and bilirubin and uroporphyrin were found in the urine; she was again admitted. Three days later more bullae appeared and the oedema diminished, and during the next week the scabs separated, leaving slightly scarred areas. The skin became progressively darker and the sclerae showed pigmentation. Light-sensitivity tests (September 11) on her back showed increased sensitivity to wave-lengths from 1,850 to $3,150 \mathrm{~A}$, maximum at $2,967 \mathrm{~A}$, and two days after the test a fresh crop of bullae appeared on her hands. Some oliguria persisted, and the uroporphyrin and indigoid pigments steadily increased. On October 2 , the day after the highest concentration of uroporphyrin was recorded, she developed sudden weakness of her arms, and, 